\title{
REANATOMIZAÇÃO DENTÁRIA E SUA IMPORTÂNCIA NOS RESULTADOS ESTÉTICOS DO SORRISO: RELATO DE CASO
}

\author{
DENTAL REHABILITATION AND ITS IMPORTANCE THE AESTHETIC RESULTS OF SMILE: CASE REPORT
}

\author{
Ary FREESE NETO'; Lucas Riza BORGES'; Victor da Mota MARTINS²; Paulo César de Freitas SANTOS-FILHO³; \\ Camila Ferreira SILVA ${ }^{4}$ \\ 1 - Acadêmicos de Odontologia pela Faculdade Morgana Potrich (FAMP), Mineiros-GO, Brasil. \\ 2 - Doutorando no Programa de Pós-Graduação - Faculdade de Odontologia Universidade Federal de Uberlândia (UFU), Uberlândia - MG, Brasil. \\ 3 - Professor na Faculdade de Odontologia Universidade Federal de Uberlândia - UFU, Uberlândia - MG, Brasil. \\ 4 - Professora do departamento de Dentística da Faculdade Morgana Potrich (FAMP), doutoranda no Programa de Pós Graduação - Faculdade de \\ Odontologia Universidade Federal de Uberlândia (UFU), Brasil.
}

\section{RESUMO}

Uma das tendências da odontologia é a área da estética que consiste na harmonização entre dentes, gengivas, lábios e face. $\mathrm{O}$ objetivo deste trabalho é relatar um caso clínico de reanatomização dentária pela técnica restauradora direta com resina composta, onde a queixa principal do paciente se baseava nos espaços interdentais e formato dos dentes na região anterior. Foi elaborado um plano de tratamento que consistiu inicialmente na realização da moldagem de estudo, enceramento diagnóstico e mock-up, onde foi detectada a necessidade de uma gengivoplastia. Em seguida foi realizado um tratamento clareador e então o procedimento restaurador pela técnica direta com resina composta. Sendo assim, obteve-se um resultado satisfatório, suprindo as expectativas do paciente, conservador, pois não houve necessidade de desgaste dentário e com grande previsibilidade técnica.

PALAVRAS-CHAVE: Resina composta; Diastemas dentários; Reabilitação estética.

\section{INTRODUÇÃO}

Desde a Antiguidade a sociedade segue padrões de beleza. Essa busca pela estética ainda persiste na atualidade, tendo como consequência uma melhor aceitação social. É por esse motivo que a busca por uma aparência agradável não é compreendida por algumas pessoas como um sinal de vaidade, mas como um aspecto importante e essencial na luta diária devido ao mundo competitivo em que se encontram ${ }^{1}$. A tendência da odontologia na área da estética consiste na harmonização entre dentes, gengivas, lábios e face. E é devido à alta demanda que o surgimento de técnicas e materiais são inevitáveis² ${ }^{2}$.

Diastemas são considerados, por muitas pessoas como fatores antiestéticos, segundo Moyers ${ }^{3}$ (1991), uma das alterações que mais incomodam as pessoas com relação ao sorriso. Tem-se como fatores etiológicos freio labial hipertrófico ou mal posicionado, dente supranumerário, microdontia, predisposição genética, entre outros fatores ${ }^{3}$. Obviamente a escolha do tratamento deve ser tomada de acordo com o fator etiológico ${ }^{4}$.

Para um correto e bom planejamento é essencial a realização dos seguintes procedimentos: radiografias para a verificação de possíveis lesões de cárie e adaptação de restaurações; tomadas fotográficas para auxiliar o profissional a analisar com tranquilidade os detalhes estéticos do paciente; modelos de estudo para uma visualização tridimensional dos elementos dentários; o enceramento diagnóstico é utilizado, para facilitar a visualização da posição, forma e proporção das futuras restaurações. Já o mock-up é fundamental para que se possa obter a aprovação do paciente, pois permite a previsibilidade final do tratamento ${ }^{5}$.

O desenvolvimento das resinas compostas e suas propriedades físicas e mecânicas permitem a mimetização das características naturais dos dentes, como a translucidez do esmalte e a opacidade da dentina ${ }^{6}$. Com esse material é possível a realização de tratamentos minimamente invasivos ou até mesmo sem preparo, permitindo assim a conservação da estrutura dentária, baixo custo para ambas as partes, menor tempo de trabalho e facilidade de reparo ${ }^{7}$.

O objetivo deste trabalho é relatar um caso clínico de reanatomização dentária pela técnica restauradora de resina composta direta, onde a queixa principal do paciente se baseava nos espaços interdentais e formato dos dentes na região anterior.

\section{RELATO DE CASO}

Paciente L.F.M., gênero masculino, 16 anos de idade, compareceu a Clínica Odontológica da Faculdade Morgana Potrich (FAMP), queixando-se do formato e espaço entre os dentes, após a assinatura do termo de consentimento livre e esclarecido pelo seu responsável, foi realizado o exame clínico e pôde-se constatar a presença de diastemas entre os incisivos centrais superiores e incisivos laterais superiores, associado a uma anatomia insatisfatória dos laterais (Figura 1). Inicialmente, foi realizada a profilaxia com escova de Robinson e pedra pomes, análise da cor 
inicial dos dentes com a escala Vitta e registro fotográfico. Após a profilaxia, foi feito uma sessão de clareamento, pela técnica de consultório, utilizando isolamento do campo operatório com barreira gengival e um afastador bucal. Foi utilizado o agente clareador a base de peróxido de hidrogênio 35\% (Whiteness HP - FGM. Joinville, SC, Brasil) de acordo com as recomendações do fabricante. Após uma sessão com três aplicações do gel clareador foi realizado uma nova análise de cor, para comparar com a cor inicial do tratamento (Figura 2). Realizou-se a moldagem das arcadas superior e inferior, com hidrocoloíde irreversível (Hydrogum - Zhermack) para a obtenção de modelos de estudo em gesso. Os modelos de gesso foram encaminhados ao laboratório para a confecção do enceramento diagnóstico. Com o mesmo em mãos, confeccionou-se um guia para a realização do ensaio restaurador (mock-up), com resina bisacrílica (Structur 3 - Voco. Porto Alegre, RS), sendo que esse procedimento proporcionou ao paciente uma prévia do resultado final do seu tratamento e aprovação do formato dos dentes (Figura 3). Nesta etapa foi avaliado a necessidade de uma plástica periodontal (gengivoplastia), realizada em seguida nos elementos 13, 12, 22 e 23. Após o período de cicatrização de duas semanas, foi iniciado o procedimento restaurador (Figura 4).

Iniciou-se com uma profilaxia utilizando pedra pomes e escova de Robinson, para remover toda a placa bacteriana presente. O procedimento restaurador foi realizado sob isolamento absoluto modificado do campo operatório e inserção do fio retrator (Retraflex - Biodinâmica) para afastamento gengival. Em seguida, foi feito o condicionamento do esmalte dental com ácido fosfórico a 37\% (Maquira) por 30 segundos, lavando posteriormente, por 60 segundos. Feito o controle de umidade no esmalte com auxílio de papel absorvente, e aplicação do adesivo convencional (Adper Single Bond - 3M. Sumaré, SP, Brasil) de 2 passos, iniciou-se então, a estratificação dos elementos. Foi inserida a resina composta de esmalte (Empress Direct A1E. Barueri, SP, Brasil) na matriz guia de silicone (Heraeus Kulzer) para confecção da face palatina, levada em posição, e fotoativada por 40 segundos em cada dente. Esta matriz guia foi removida, e então a resina de dentina (Empress Direct A1D. Barueri, SP, Brasil) foi inserida, promovendo uma mimetização da estrutura natural dos elementos, e novamente fotoativada por mais 40 segundos em cada dente. Uma última camada de resina de esmalte (Empress Direct A1E. Barueri, SP, Brasil) foi inserida reproduzindo o formato do dente, conforme o enceramento, e pela última vez fotoativação por 40 segundos em cada dente (Figura 5).

Após o procedimento restaurador, foram checados os contatos oclusais e realizado o acabamento das restaurações com pontas diamantadas FF (Microdont), discos solft-lex (Pop on - 3M/ ESPE) e broca multilaminada 30 lâminas n9714FF. Nas faces interproximais o acabamento foi feito com tiras de lixa de resina. O polimento foi realizado com taças de borracha, escova de carbeto de silício, disco de pelo de cabra, disco de feltro (Diamond Flex) e pasta de polimento (Diamond Excel), o que proporcionou uma lisura e brilho superficial semelhante aos elementos naturais. As interproximais foram polidas com pasta de polimento e fita interdental (Figura 6).
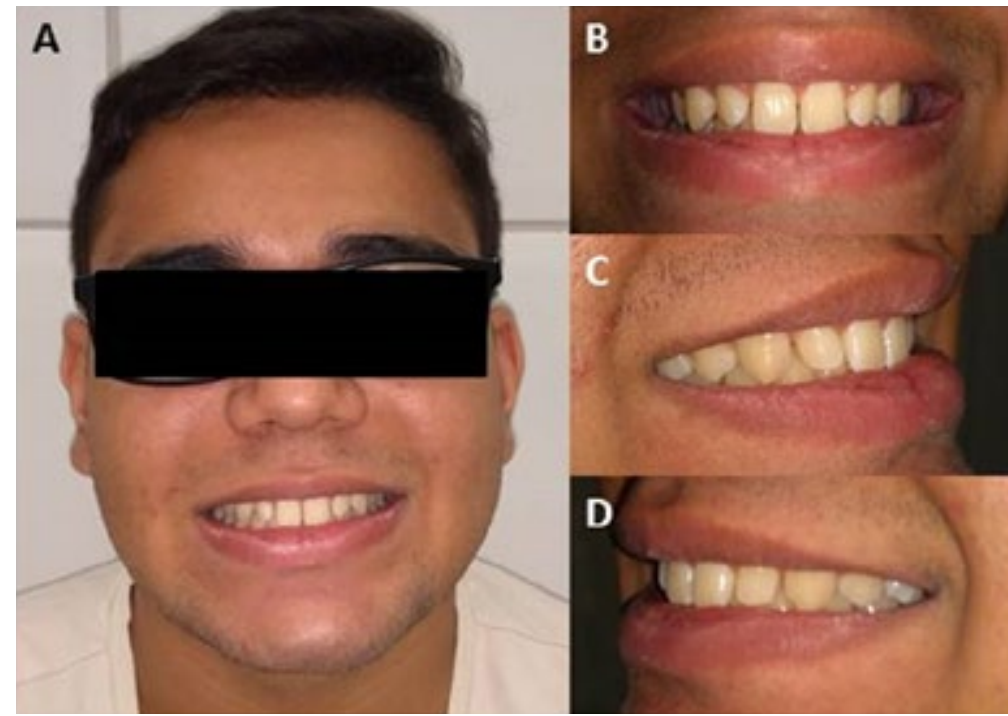

D

Figura 1A - Foto fronta inicial; B - Sorriso aproximado; C - Sorriso aproximado lado direito; D - Sorriso aproximado lado esquerdo

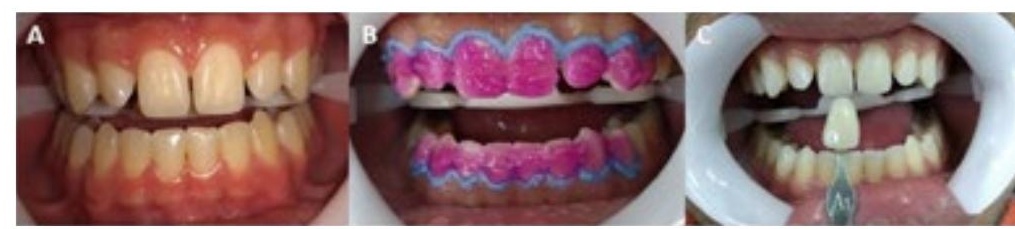

Figura 2A - Foto inicial antes do tratamento clareador; B - Aplicação do gel clareador; C - Seleção de cor após uma semana do clareamento

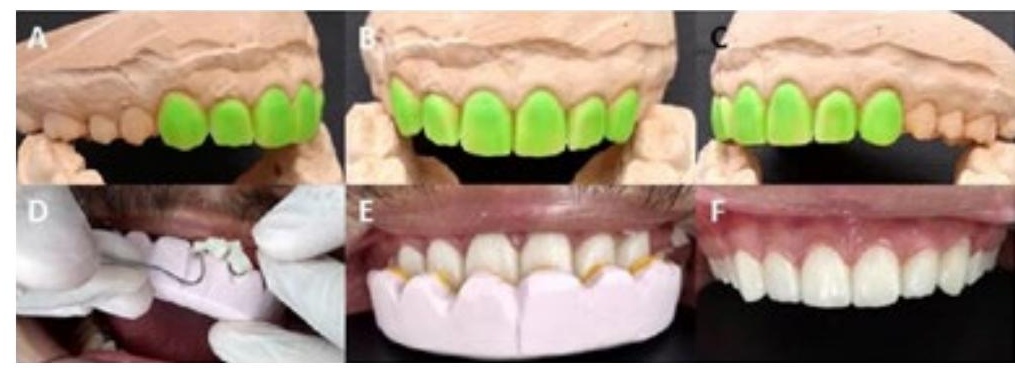

Figura 3A, B e C - Enceramento diagnóstico; D - Remoção dos excessos da resina bisacrílica; E e F - Mock-up

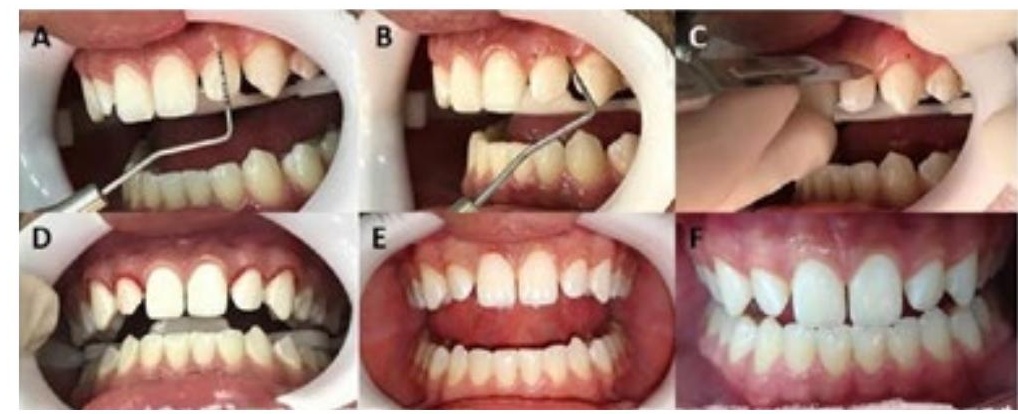

Figura 4A - Sondagem inicial; B - Pontos sangrantes; C - Incisão; D - Aspecto final após gengivoplastia; E - Após uma semana; F - Após duas semanas 


\section{DISCUSSÃO}

A redução no índice da cárie dentária, associada a uma população que, de modo geral, clama cada vez mais pela Odontologia estética, faz com que a natureza e a extensão do tratamento odontológico evoluam, realçando o tratamento cosmético. Sabendo que a estética envolve o estudo da beleza e da resposta emotiva a ela, o tratamento dental cosmético engloba componentes artísticos e subjetivos para arquitetar a ilusão da beleza ${ }^{1}$. Dentre as expressões faciais, o sorriso se destaca, sendo ele o responsável por expressar humor, agradecimento, alegria e prazer ${ }^{8}$. Segundo Pagani e Bottino ${ }^{1}$ (2003), a insatisfação com a estética dental pode levar a perda da autoconfiança, uma queda na autoestima do indivíduo, afetando a vida social, educacional e cultural, sendo que ao contrário, um sorriso esteticamente aceitável aumenta até mesmo a aceitação do indivíduo pela sociedade, melhorando a impressão inicial. $\mathrm{O}$ paciente relatado no caso acima também entra nessa realidade, pois não possuía doença cárie e apesar da pouca idade já se preocupava com a estética e desarmonia do seu sorriso.

De acordo com Moskowitz e Nayyar ${ }^{9}$ (1995), para a realização de um tratamento cosmético é necessário à compreensão dos princípios estéticos para planejar e executar o novo sorriso, sendo eles, a linha do sorriso, linha média, posicionamento da borda incisal de cada elemento, o contorno gengival, o zênite gengival, triângulo papilar, contato interdental, textura dos dentes, forma e contorno dos mesmos e a forma dos espaços interdentais. De acordo com o trabalho de Suzuki; Machado e Bittencourt $^{10}$ (2011), um sorriso esteticamente agradável consiste no lábio superior expondo toda a coroa clínica dos incisivos centrais superiores exibindo $1 \mathrm{~mm}$ de gengiva, sendo aceitável até 3 $\mathrm{mm}$. Para os sorrisos que ultrapassam esse limite pode-se contar com algumas opções de tratamento, tais como: gengivoplastia, gengivectomia, tratamento ortodôntico e cirurgia ortognática ${ }^{11}$. No exame clínico inicial constataram-se as seguintes características: linha média alinhada, uma pequena giro-versão do elemento 12 , ausência de contatos interdentais de aproximadamente 0,5 $\mathrm{mm}$ entre os incisivos centrais (IC), de 1,5 mm entre os incisivos centrais e laterais, e de $1 \mathrm{~mm}$ entre incisivos laterais (IL) e caninos. Também notou-se uma excelente textura nos IC e caninos, porém um formato anatômico insatisfatório nos IL. O tamanho da coroa clínica dos IC apresentaram-se satisfatórias, mas dos IL e caninos verificou-se a necessidade de um pequeno aumento da coroa clínica.

Para que todas essas análises fossem feitas, foi necessário utilizar métodos de diagnóstico e planejamento. Segundo Fradea$\mathrm{ni}^{12}$ (2006), o enceramento diagnóstico é uma ferramenta muito utilizada para se ter previsibilidade dentro da odontologia. Através dele é possível realizar o ensaio restaurador (mock-up) que se trata de uma alternativa para mostrar ao paciente a forma final dos dentes antes de iniciar o tratamento. Através dele pode-se confeccionar também a matriz guia de silicone, que servirá como guia para as restaurações diretas. No presente caso citado acima, o enceramento diagnóstico foi de grande importância para realização do ensaio restaurador, o que possibilitou ao paciente juntamente com o dentista visualizar o resultado final do tratamento, mostrando a necessidade de gengivoplastia além de guiar nas restaurações diretas em resina composta.

Um sorriso harmônico não é construído baseado somente nos dentes clareados e alinhados. Lábios, mucosa e gengiva fazem

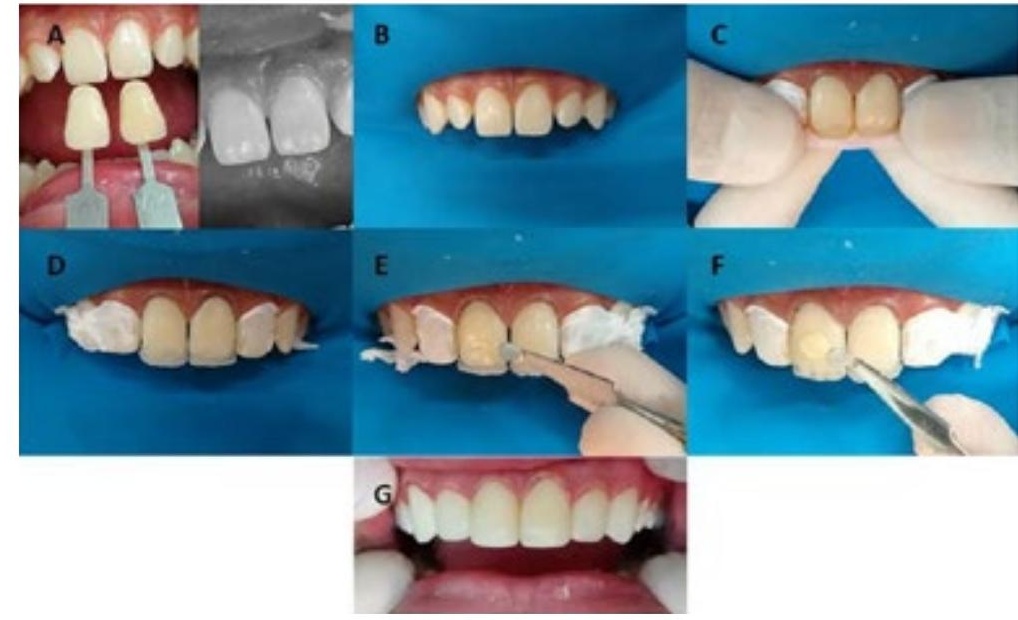

Figura 5A - Seleção de cor; B - Isolamento absoluto modificado; C - Matriz guia de silicone; D - Conchas palatina de esmalte; E - Inserção da camada de resina A1D; F - Inserção da camada de resina A1E; G - Aspecto final sem acabamento e polimento

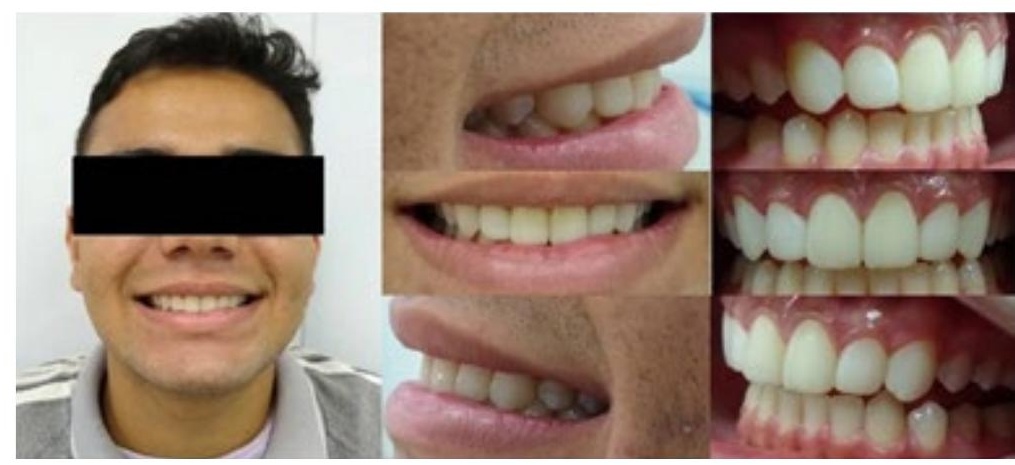

Figura 6 - Aspecto final

parte desse conjunto que pode construir um sorriso estético. Deve-se então preocupar com os dentes e com a gengiva (estética vermelha) para que a harmonia do sorriso seja completa. A gengivoplastia é a cirurgia que visa alterar o contorno gengival, proporcionando uma agradável simetria entre tecidos gengivais e dentários, indicada quando há ausência de doença periodontal, sendo uma técnica de fácil execução, trazendo bons resultados na harmonia do sorriso ${ }^{13}$. A cirurgia periodontal visa um melhor prognóstico para alguns casos, sendo assim, de grande importância para casos estéticos que necessitam de uma remodelação do tecido gengival ${ }^{14}$.

Há uma crescente busca por estética na odontologia, pois várias pessoas não estão satisfeitas com o seu sorriso, seja por dentes mal posicionados, anatomias irregulares ou que queiram dentes mais brancos ${ }^{15}$. O clareamento dental é um procedimento muito importante previamente às restaurações estéticas, sendo uma técnica simples, com grande evidência científica sobre sua efetividade ${ }^{16}$. Classificado em clareamento caseiro ou de consultório, as duas técnicas são motivo de especulações sobre os seus benefícios, riscos, contraindicações, efeito clareador, e indicação da técnica ${ }^{17,18}$. A associação dessas técnicas é significativa quando pacientes e profissionais desejam um resultado rápido e satisfatório alcançando em poucas sessões o resultado esperado ${ }^{19,20}$. A mudança de cor do substrato dental foi de grande importância no caso citado, pois a partir dessa mudança foi possível utilizar 
resinas com boas propriedades ópticas proporcionando ao paciente um resultado mais estético e natural.

Atualmente, existem diversas opções de resinas compostas no mercado odontológico com excelentes propriedades, nos últimos anos os fabricantes têm buscado melhorar suas propriedades ópticas para reproduzir as características do dente natural ${ }^{21}$. A resina composta tem sido bastante indicada em tratamentos estéticos devido às suas características satisfatórias e semelhantes à estrutura dental, sua biocompatibilidade e sua durabilidade. Além de possuir uma excelente estética, com preservação da estrutura dentária, o seu custo é baixo comparado às restaurações indiretas ${ }^{22}$.

Segundo Dietschi ${ }^{23}$ (1995) e Terry ${ }^{24}$ (2000) para conseguir uma excelente restauração do ponto de vista estético, é preciso compreender as dimensões da cor, características ópticas e os diferentes materiais restauradores. Dentre as características ópticas da resina composta, o matiz é definido como o tom da cor, o croma como quantidade de pigmentos brancos contido na escala do matiz e o valor, ou brilho, diferencia cores claras das escuras, ou seja, quantidade de preto e branco existentes na resina $^{25}$. O esmalte dental é um tecido com difícil reprodução devido às suas características ópticas. Quando a luz atinge a superfície do esmalte se comporta com uma dinâmica própria, variando desde a translucidez até a opacidade, opalescência e fluorescência ${ }^{26}$.

A longevidade das restaurações é influenciada por vários fatores, como por exemplo, o conhecimento dos materiais e da técnica a ser utilizada, a habilidade do profissional e a colaboração do paciente. Todos esses requisitos são de grande importância para que não haja falhas em um curto espaço de tempo ${ }^{27}$. Uma das características que influenciam na longevidade das restaurações é a lisura superficial gerada após a etapa de acabamento e polimento; esta etapa evitará que se acumule placa bacteriana nas margens das restaurações, gerando uma maior longevidade da restauração ${ }^{28}$. O acabamento consiste na redução da restauração, permitindo um contorno grosseiro, com o objetivo de alcançar a forma anatômica desejada; já o polimento consiste na redução da rugosidade superficial provocada pelos instrumentos de acabamento ${ }^{29}$. A resina que foi utilizada neste relato de caso possui uma excelente propriedade estética, pois proporcionou um brilho natural antes mesmo do polimento.

A associação de métodos de planejamento além do conhecimento das possibilidades e limites que o tratamento restaurador pode proporcionar é essencial para uma correta indicação e previsibilidade do resultado final. O sucesso do caso descrito só foi possível graças à utilização de diferentes técnicas e alternativas, na tentativa de superar as expectativas do paciente.

\section{CONCLUSÃO}

A terapia estética de clareamento dental seguido por gengivoplastia e restaurações diretas de resina composta para o fechamento de diastema na região anterior foi um tratamento efetivo, capaz de restaurar a forma, a função e a estética dental, contribuindo para o sucesso clínico e satisfação do paciente.

\section{REFERÊNCIAS}

01. Pagani C, Bottino MC. Proporção áurea e a odontologia estética. Jornal Brasileiro de Dentística \& Estética. 2003; 2(5): 80-85.
02. Chou JC, Nelson A, Katwal D, Elathamna EM, Durski MT. Effect of smile index and incisal edge position on perception of atractiveness age groups. J Oral Rehabil. 2016; 43 (11):855-862.

03. Moyers RE. Ortodontia. 4. ed. Rio de Janeiro: Guanabara Koogan;1991.794 p.

04. Proffit WR. Ortodontia Contemporânea. 5. ed. São Paulo: Pancast; $1991.589 \mathrm{p}$.

05. Higashi C, Gomes JC, Kina S, Andrade OS, Hirata R. Planejamento estético em dentes anteriores. In: Mivashita E, Mello AT. Odontologia estética: planejamento e técnica. Artes médicas; 2006. p. 139-54.

06. Paolone G, Saracinelli M, Devoto W, Putignano A. Esthetic direct restorations in endodontically treated anterior teeth. Eur J Esthet Dent. 2013; 8(1): 44-67.

07. Guagliato PS, Soares PV, Calixto LR. Restaurações estéticas diretas em dentes anteriores. Estética odontológica soluções clínicas. Nova Odessa: Editora Napoleão; 2012. p. 1-34.

08. Peck S, Peck L, Kataja M. The gengival smile line. The Angle Orthodontist. 1992; 62(2):91-100.

09. Moskowitz ME, Nayyar A. Determinants of dental esthetics: rational for smile analysis and treatment. Compend Contin Educ Dent. 1995; 16(12):1164.

10. Suzuki L, Machado AW, Bittencourt MAV. Avaliação da influência da qualidade de exposição gengival na estética do sorriso. Dental Press J Orthod. 2011; 16(5): e1-10.

11. Braga MS, Nascimento JMQ, Camargo EB, Veloso Filho JMSC, Falcão EP, Zuzza EP, Pires JR. Cirurgia plástica periodontal para correção de erupção passiva alterada. Braz J Periodontol. 2015; 7(5):505-509.

12. Fradeani M. Reabilitação estética em prótese fixa: análise estéticauma abordagem sistemática para o tratamento protético. São Paulo: Quintessence; 2006.

13. Carranza FA, Takei HH. Cirurgia mucogengival. In: Carranza FA, Newman MG. Periodontia clínica. Rio de Janeiro: Guanabara Koogan; 1997. p. 695-718.

14. Sousa CP, Garzon ACM, Sampaio JEC. Estética periodontal: relato de um caso. Revista Internacional de Cirurgia e Traumatologia Bucomaxilofacial. 2003; 1(4):262-7.

15. Mollica FB, Rocha DM, Travassos AC, Valera MC, Araujo MAM. Temperature variation in pulp chamber during dental bleaching in presence or absence of light activation. Rev odonto ciênc. 2010; 25(4):382-385.

16. Baratieri, Luiz Narciso et al. Clareamento dental. Rio de Janeiro: Santos; 1994.

17. Mota CBO, Carvalho NR, Brasil CMV, Teixeira HM, Beatrice LCS, Nascimento ABL. Clareamento Caseiro Supervisionado: Revisão de Literatura. International Journal of Dentistry. 2008; 7(3): 178- 183.

18. Nunes MF, Mastti AS, Rolla JN, Soares CG, Conceição EN. Avaliação clínica do efeito de duas técnicas de clareamento dental em consultório utilizando peróxido de hidrogênio. Rev Fac Odontol Porto Alegre. 2009; 50(2):8-11.

19. Zanín F, Freitas PM, Aranha ACC, Ramos TM, Lopes AO. Clareamento de dentes vitais. Rev Assoc Paul Cir Dent. 2010; 64(5): 338-45.

20. Figueiredo JLG, Niedermaier KC, Zaia WLS. Clareamento dental: relato de caso clínico avaliado pela análise espectrofotométrica. Rev dental press estét. 2007; 4(4):92-100.

21. Höland W, Rheinberger V, Apel E, Ritzberger C, Rothbrust F, Kappert H, Krumeich F, Nesper R. Future perspectives of biomaterials for dental restoration. Journal of the European Ceramic Society. 2009; 29(7):1291-1297. 
22. Pontes AP, Mainieri ÉT, PachecoJFM, Martins JL, Shinkai RAS, Chiada Mainieri V. Rugosidade superficial de compósitos microparticulados e nanoparticulados após acabamento e polimento. RGO. 2009; 57(2): 179-182.

23. Dietschi D. Free-hand composite resin restorations: a key to anterior aesthetics. Practical Procedures e Aesthetic Dentistry. 1995; 7(7):15-25.

24. Terry DA. Enhanced resilience and esthetics in a class IV restoration. Compedium of Continuing Education Dentistry Supplent. 2000; (26):19-25.

25. Medeiros CGG. Princípios básicos de estética aplicados na Dentística restauradora. Revista Odontológica do Brasil Central. 1999; 8(25): $19-22$.

26. Villarroel MJ. Óptica dos materiais restauradores. In: Congresso Internacional de Odontologia de Ponta Grossa; 2004. p. 81.

27. Miyashita E, Mello AT. Odontologia estética: planejamento e técnica. Rio de Janeiro: Artes médicas; 2006.

28. Pedrosa SF, Soares C.J, Souza MM, Moreira Filho N. Avaliação da rugosidade de superfície da resina composta micropartícula após o polimento. Rev Bras Odontol. 1993; 50(5):46-8.

29. Yap AU, Lye KW, Sal CW. Surface of tooth-colored restoratives polished utilizing different systems. Oper Dent. 1997; 22 (6): 260-5.

\section{ABSTRACT}

One of the trends of dentistry, is the area of aesthetics, consists of harmonization between teeth, gums, lips and face. The objective of this study is to report a clinical case of dental reanatomization using the direct composite resin restorative technique, where the patient's main complaint was based on interdental spaces and tooth format in the anterior region. For the solution of the case the following procedures were performed: study molding, diagnostic waxing, mock-up, through this procedure the need for a gingivoplasty was detected, followed by a bleaching treatment and then the restorative procedure by the direct resin technique composed. Thus, a satisfactory result was obtained, supplying the patient's expectations, conservative because there was no need for dental wear and with great technical predictability.

KEYWORDS: Composite resin; Diastema dental; Aesthetic rehabilitation.

\section{AUTOR PARA CORRESPONDÊNCIA}

Camila Ferreira Silva

Av. Antônio C. Paniago, 65, Setor Mundinho - Centro,

Mineiros - GO, Cep.: 75830-000

Telefone: (34) 996610582

E-mail: ferreirascamila@outlook.com 